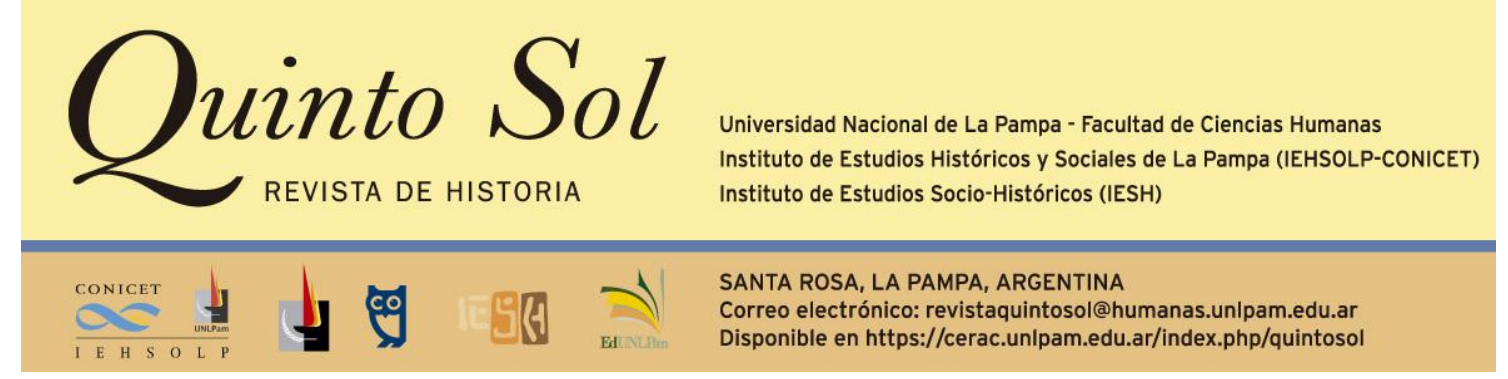

Quinto Sol, vol. 26, $\mathrm{n}^{\circ}$ 1, enero-abril, ISSN 1851-2879, pp. 1-5

http://dx.doi.org/10.19137/qs.v26i1.6290

Esta obra se publica bajo licencia Creative Commons 4.0 Internacional. (Atribución-No ComercialCompartir Igual)

\title{
Federico Martocci. Con los pies en el surco. Instituciones estatales y actores de la ciencia agropecuaria en La Pampa (1958-1983). Prometeo, 2021, 280 páginas.
}

\author{
Hebe Vessuri \\ Universidad Nacional Autónoma de México. Centro de Investigaciones en Geografía Ambiental México \\ México \\ Correo electrónico: hvessuri@gmail.com
}

Desde la creación del Ministerio de Agricultura en 1898, la asociación entre agricultura, ganadería, población y tierra se sistematizó a través de instituciones y programas de colonización y extensión. El diseño industrial de Argentina en la primera mitad del siglo XX ocurrió de la mano del sector agroindustrial que reguló la tierra, las actividades, la colonización y la población. La revisión temporal de la idea de extensión rural a través de una obra como la revisada aquí permite apreciar una faceta interesante de la sociedad provincial a través de una lente particular. ¿Cómo se expresaron los conocimientos científicos en las ideas de la extensión en el tiempo, reproduciendo y/o redefiniendo ideas técnicas e ideologías dominantes? ¿Cómo dibujaron mundos y formas de relacionamiento? ¿De qué maneras los practicantes de la ciencia y la tecnología contribuyeron a proyectos de extensión/desarrollo? En las primeras décadas del siglo XX ya se hacía investigación y extensión, seguramente no en la escala necesaria, aunque tampoco era algo desestimable. Sin embargo, hubo un cambio significativo en las ciencias agrícolas de la región, que fue parte de un proceso más amplio generalizable a América Latina, que resultó en su reconfiguración entre 
1940 y 1960. En todas partes se enfatizaba una gran necesidad de investigadores formados y era evidente la urgencia por tener más especialistas competentes, particularmente en las ciencias agrarias.

Desde los días de la Reforma de 1918 la idea de la extensión se había percibido como parte de la función de educar al pueblo soberano. A partir de los años cincuenta pasó a ser instrumental para la introducción y difusión de conocimientos transnacionales bajo un concepto renovado. Se suponía que la ilustración de la universidad y de los organismos técnicos del Estado podía llegar a la población, especialmente en relación con la producción de riqueza y bienestar, traduciendo el conocimiento técnico disponible a nivel internacional. La idea del extensionismo se reflejó en un imaginario de hombres, tecnologías y naturalezas en torno a la ruralidad, marcado por el progreso técnico.

En el caso de la pampa ese imaginario se desdobló en, por un lado, el de indios y gauchos en medio de vastas soledades y, por el otro, el de riquezas naturales inmensas resultado de la explotación agrícola-ganadera, "el granero del mundo". Este libro de Federico Martocci indaga en valiosos aspectos del segundo; el foco está en la historia agraria pampeana, explorando instituciones educativas, científicas y sociales, así como su papel en la generación, difusión e incorporación de conocimientos y tecnologías al agro. Aporta nuevos elementos al corpus interpretativo de la ciencia y la tecnología, que todavía tiene una producción limitada en el país, más aún en lo relacionado con el mundo agrario, sobre todo de una región periférica tanto desde el punto de vista geográfico como productivo, como lo es la provincia de La Pampa. El punto de partida del autor es el basamento técnico constituido en el interior del país desde finales del siglo XIX hasta mediados del siglo XX, en el proceso de construcción del Estado nacional. Arranca en el momento de transformación del Territorio Nacional de La Pampa en provincia, aproximadamente coincidente con el cambio de la agricultura cerealera a la ganadería como actividad económica más importante, y la búsqueda de fuentes alternativas de producción en el "oeste de la provincia, que había quedado prácticamente ajeno a la mirada oficial". El sesgo particular que le da el autor al estudio es su atención a la contribución de técnicos que trabajaron muy cercanos a la producción, como lo remarca en el título sugerente "con los pies en el surco". El papel en el mundo rural de esa provincia de técnicos como Guillermo Covas, Juan Carlos M. Lasalle, Andrés Ringuelet, Héctor F. Peters, Héctor D’Adam, Enrique Álvarez Beramendi, Juan Pedro Torroba y Ubaldo Farías y otros es reconocido en su importancia en los distintos momentos considerados en la obra. Sus trayectorias y las de otros profesionales en un arco variado de funciones combinaron la función técnica en el Estado como funcionarios y/o docentes e inclusive, en algunos casos, trabajando en el sector privado.

El interés de Martocci es rastrear la preocupación del nuevo Estado provincial por dar respuesta a los problemas agropecuarios que venían agobiando al territorio desde comienzos de los años treinta, como consecuencia de la larga sequía y la pérdida repetida de las cosechas y erosión de los suelos. Claramente, la crisis de la agricultura de secano parece haber tenido un impacto mucho mayor en La Pampa que en otras provincias de la región pampeana. Justamente el cometido que se propone Martocci es revisar el rol de las instituciones educativas y científico-técnicas en el Estado provincial en su interacción con los productores. No es casual que la Facultad de Agronomía haya sido de las primeras en constituirse en la nueva universidad. Desde luego el INTA tuvo 
un papel central tanto en investigación como en extensión. No obstante, la mirada del autor en este caso se concentra no en esa institución, que ya ha recibido la atención de otros autores, sino en su interacción con las diferentes instituciones provinciales y los productores de la zona, así como en el diseño e implementación de políticas específicas para el sector rural. La búsqueda de alternativas productivas en el oeste pampeano y el desarrollo de estudios para conservar los suelos se convirtieron a partir de los años cincuenta en verdaderos desafíos de la agenda social que según los momentos el Estado tomará en cuenta tratando de resolverlos, especialmente a través de la vinculación del INTA con la Facultad de Agronomía.

A partir del reconocimiento de antecedentes en materia de institucionalización agropecuaria, el trabajo comienza reconstruyendo las acciones del gobernador radical Ismael Amit en relación con la actividad agropecuaria, el INTA y las actividades iniciales de formación de profesionales para el agro en la nueva Universidad provincial. También considera la opinión de la Asociación Agrícola Ganadera de La Pampa (AAGLP), una entidad rural relevante en la provincia. Luego considera la ciencia agropecuaria en el lapso 1966-1976, de expansión bovina y difusión del pasto llorón, una forrajera de grandes ventajas conservacionistas, y los esfuerzos de mejora de los servicios de extensión agropecuaria. Todo esto ocurría en un contexto de conflictividad y rápidos cambios políticos, especialmente evidentes en el lapso 1976-1983, con el régimen cívico-militar que interrumpió las actividades de extensión rural en 1980 e intervino políticamente las Facultades de Agronomía y Ciencias Veterinarias de la UNLPam.

En el lapso 1958-1966 se vivió un esfuerzo notable de incentivación de la producción y diversificación de la economía del territorio, siguiendo de alguna forma los lineamientos que en el nivel nacional propugnaba el gobierno desarrollista de Arturo Frondizi. La valorización del personal con credenciales académicas en el gobierno provincial y el apoyo social a la nueva Universidad ayudaron a instalar en el medio local la idea de que con ciencia y tecnología las economías de la provincia saldrían del estancamiento en que estaba sumida. Se confiaba que la presencia de técnicos impulsaría las riquezas potenciales del territorio pampeano. A mediados de los sesenta, el INTA había avanzado en la comprensión de la erosión y la conservación de la humedad en el suelo, y había llevado adelante acciones concretas para difundir los resultados de sus investigaciones entre los productores.

En la difícil y turbulenta década entre 1966 y 1976 se dieron procesos de sentido contrapuesto, ya que por un lado se observaron los efectos positivos del desarrollo de capacidades en la provincia con la difusión de forrajeras aptas, la menor incidencia de la erosión en la sequía de 1965 con respecto a la de 1937-1938, en relación con la cual se atribuía ampliamente a Covas el gran impacto del rastrón poceador en la elevación del área sembrada con pasto llorón, coincidente con la transición de la ganadería ovina a la bovina. Por el otro, hubo problemas en la aplicación de las leyes y resultados alcanzados por las políticas aplicadas, especialmente por su poca continuidad debido a la inestabilidad institucional del país en esos años. Sin embargo, con la creación del Servicio de Extensión y Fomento Agropecuario (SEyFA), se aceleró la circulación de la información útil para los productores agrarios. La zona de influencia de la EEAA siguió siendo la comprendida entre los Departamentos del este pampeano y algunos Partidos del oeste bonaerense, en tanto que los productores del extremo oeste provincial permanecieron siéndoles prácticamente ajenos. 
En el período de gobierno militar de 1976 a 1983, a pesar de la propaganda inicial, el oeste dejó de ser visto por ellos como terreno propicio para la subversión, convirtiéndose en el principal objetivo de la política oficial de desarrollo ganadero de la provincia. Sin embargo, a pesar de contar con el beneficio de los conocimientos adquiridos sobre la región gracias a la construcción de capacidades e información en las décadas anteriores, no se logró ampliar la frontera productiva, aspiración de los gobernantes provinciales desde mediados del siglo. Con la llegada de los militares al poder en 1976 la relación entre la Universidad y la Asociación Argentina de Consorcios Regionales de Experimentación Agrícola (AACREA) se hizo más intensa, entre otras cosas porque quienes estaban en el gobierno eran asesores o integrantes de Consorcios Regionales de Experimentación Agrícola (CREA), tenían vinculación directa con entidades rurales y eran críticos de la intervención estatal en materia agropecuaria. En la última etapa de la dictadura se difundió entre los llamados grupos cooperativos "la metodología CREA", y las Agronomías Departamentales (excepto las del extremo oeste) se transfirieron al INTA, en el momento en que la institución atravesaba una situación de notables cambios, cuando muchas de sus políticas y programas de extensión ya habían sido desarticulados por las intervenciones militares.

Entre la batería de instituciones y programas con los que el aparato estatal provincial se proponía lograr las aspiraciones colectivas de la "conquista del desierto" estuvieron temas como la protección del bosque nativo, la formación de técnicos para el agro cuya actividad favoreciera la revitalización de la producción primaria (base de la economía local), la búsqueda de alternativas productivas en otras zonas de La Pampa y, especialmente, la conservación del suelo en un espacio marginal de la región pampeana. Fueron muchas las limitaciones que tuvo este esfuerzo, pero también hubo resultados positivos que en diversos momentos permitieron desplegar sinergias interinstitucionales y con los productores agropecuarios.

Martocci llama la atención sobre el poco prestigio y estatus social que tenían las carreras de ingeniero agrónomo y médico veterinario en La Pampa, aún a comienzos de los ochenta, algo que esos profesionales vivieron en distintos contextos. Su aceptación y respeto como interlocutores válidos por los productores y su legitimación como integrantes del corpus científico y técnico de la Universidad fue característicamente problemático derivando en distintos patrones de evaluación y legitimación. El autor rescata la noción de técnico como concepto que califica como nativo, identificándolos, como ya dijimos, en sus trayectorias formativas, sus aportes a la investigación y la docencia, y en algunos casos inclusive sus orientaciones políticas, en la multiplicidad de roles cumplidos en la vida pública, la esfera cultural, el desempeño privado de la profesión y en algunos casos la producción agropecuaria propiamente dicha. Pasaron décadas hasta la profesionalización del ingeniero agrónomo en el contexto local.

Los productores, como objeto de atención de las carreras de agronomía, muchas veces son descriptos como rechazando los mensajes de los extensionistas o simplemente indiferentes. Sin embargo, eran cualquier cosa menos sujetos que pasivamente ignoraban o aceptaban las recomendaciones técnicas. Entender la naturaleza de la conducta de los agricultores es fundamental para poder situar mejor la naturaleza y el papel de la extensión en el siglo XX. En Argentina, como en otros contextos, eran pocos los agricultores que tenían educación agrícola formal en los años treinta a sesenta, y casi todos desconfiaban de los agricultores leídos o librescos -los 
agrónomos-, representantes de una profesión nueva que provenía del ámbito urbano. Sin embargo, es menester reconocer que el trabajo mental de hacer agricultura envolvió siempre un conjunto de habilidades más importantes que el esfuerzo físico. La tarea fundamental del agricultor no ha sido tanto el trabajo físico sino cómo concebir qué hacer, de qué manera y cuándo.

En las tempranas décadas de la primera mitad del siglo XX la agronomía y la veterinaria habían comenzado a profesionalizarse en el país, en un proceso ligado al proyecto de construcción de la nación. En el clima político y económico de la Argentina de los años cuarenta y cincuenta, el gobierno nacional buscó modernizar, nacionalizar e integrar a sus poblaciones y naturalezas. La idea era que los científicos y los agentes extensionistas produjeran conocimientos bajo el supuesto de asegurar el interés colectivo, desarrollar regulaciones y optimizar poblaciones y territorios, en asociaciones que se esperaba serían beneficiosas. Se procuraba crear el excedente nacional extendiendo el valor sobre el territorio, volviéndolo productivo. Distintas disciplinas aplicadas se institucionalizaban de forma politizada, contribuyendo al imaginario nacional al servicio de los intereses del Estado nacional. La función pública suponía el servicio técnico sobre sociedades, paisajes, productividad y poblaciones. Martocci nos proporciona un mapa de las instituciones y redes en el lapso considerado, y de los profesionales que les dieron vida. Quizás nos quedamos con ganas de más respecto a cómo se dio la institucionalización de la investigación agronómica y veterinaria en el seno de la Universidad y el INTA, y los alcances del esfuerzo para lograr una cierta especialización regional, pero el análisis meticuloso de las dificultades y obstáculos en el camino de esa institucionalización son muy útiles y sugerentes para entender las dinámicas que siguió la investigación universitaria no sólo en este sino también en otros contextos provinciales y en el ámbito nacional. Las y los lectores interesados en esta temática encontrarán material muy sustancioso para seguir profundizando en la reconstrucción e interpretación de la historia de la ciencia y la tecnología agraria de nuestro país. 